\title{
O Campo de Estrelas: um híbrido situado em algum lugar entre o Livro Ilustrado e a Novela Gráfica
}

\author{
RADÜNZ, Karen; Bacharela em Design Gráfico; Universidade Federal de Pelotas \\ karenradunz@gmail.com \\ Orientadora: HERZOG, Vivian; Mestra em Artes Visuais; Universidade Federal de Pelotas \\ vivianherzog@gmail.com
}

Palavras-Chave: Livro ilustrado, Novela gráfica, Design autoral, Design gráfico.

\begin{abstract}
Resumo: O presente artigo apresenta considerações acerca do chamado conto-ilustrado, um híbrido situado entre o livro ilustrado e a novela gráfica, que consiste em um conjunto de fragmentos ilustrados produzidos a partir de um conto escrito. Neste artigo, será apresentado o conto-ilustrado junto a uma reflexão sobre a sua produção prática, considerando, também, ao longo do processo, reflexões obtidas a partir de estudos referentes à área do livro ilustrado e da novela gráfica, contemplando, principalmente, aspectos relacionados ao design autoral.
\end{abstract}




\section{Introdução: o que me move e como isso acontece}

O presente artigo origina-se de um trabalho de conclusão de curso de Design Gráfico, que consistiu na produção de um projeto de design editorial organizado em um volume único composto por uma parte teórica e uma prática. Neste artigo, será apresentado especificamente o chamado conto-ilustrado, fase que corresponde à parte prática do projeto citado, bem como considerações feitas no que tange à área do livro ilustrado e da novela gráfica, conceitos que serão apresentados posteriormente.

Essa produção prática do conto-ilustrado, que caracterizo como "um híbrido situado em algum lugar entre o livro ilustrado e a novela gráfica", compreende a elaboração de uma série de fragmentos ilustrados a partir de um conto escrito por mim, intitulado O Campo de Estrelas. Esses fragmentos estão representados aqui por quatro duplas de páginas ilustradas, correspondentes a pontos relevantes da história.

Dentro dos aspectos desenvolvidos na elaboração do trabalho, alguns objetivos se fazem recorrentes: a compreensão do livro ilustrado e da novela gráfica para a produção de ilustrações de um conto próprio; o entendimento e compreensão dessas duas áreas como objetos de design que condensam linguagem literária e linguagem visual; e a relação entre essas categorias com o design autoral.

Sendo esse um trabalho de cunho autoral, serão abordadas concepções relativas ao design autoral a partir do viés de Lúcia Weymar (2010). Ainda exploro, a partir das categorias de Michael Rock (1996), também presente nos estudos de Weymar, a compreensão do livro de artista e os conceitos da ilustração como uma das possibilidades do design autoral. Conceitos centrais, como os de livro ilustrado e novela gráfica, são abordados a partir de Will Eisner, em Quadrinhos e Arte Sequencial (1989), Santiago García, em O romance gráfico (2012) e Sophie Van der Linden, em Para ler o livro ilustrado (2011).

Utilizando alguns conceitos de Paul Feyerabend (1977) recortados sob a visão de Marcos Beccari no texto Contra o método - o anarquismo epistemológico de Paul Feyerabend (2010), construí minha própria metodologia, que não segue um padrão preestabelecido, mas desenvolve-se e adequa-se de acordo com o andamento do processo, respeitando o fluxo de criatividade e produção. Conforme Beccari (2010) a partir dos conceitos de Feyerabend,

[...] ao invés de tentar adaptar um projeto ao método preestabelecido, [é] mais sincero ao fazer design o ato livre de se gerar hipóteses e conjecturas que, naturalmente, vão sugerir determinados métodos a serem utilizados em função do projeto (BECCARI, 2010).

\section{Esclarecendo termos e emprestando conceitos}

\section{O livro ilustrado e a novela gráfica}

\section{UFPEL}




\section{SULDESIGN CIENTÍFICO 2017}

VIII Suldesign - encontro sul-americano

O livro ilustrado é considerado uma categoria ampla, englobando, também, a área das novelas gráficas e das histórias em quadrinhos, segundo Van der Linden (2011). A fim de meIhor delimitar o objeto, a autora (2011) cita classificações nas quais podemos encontrar o livro ilustrado: um exemplo é a chamada Conjunção, na qual este artigo tem seu foco, sendo nela em que "[...] textos e imagens já não se encontram dispostos em espaços reservados, e sim articulados numa composição geral [...]" (VAN DER LINDEN, 2011, p. 69). Nela, "[...] os enunciados ficam entremeados, e não justapostos, e os textos, de modo literal, integram a imagem" (VAN DER LINDEN, 2011, p. 69), possibilitando que o leitor tenha um entendimento imagético e textual concomitantes.

Pode ser percebida, também, uma relação com a página dupla, que

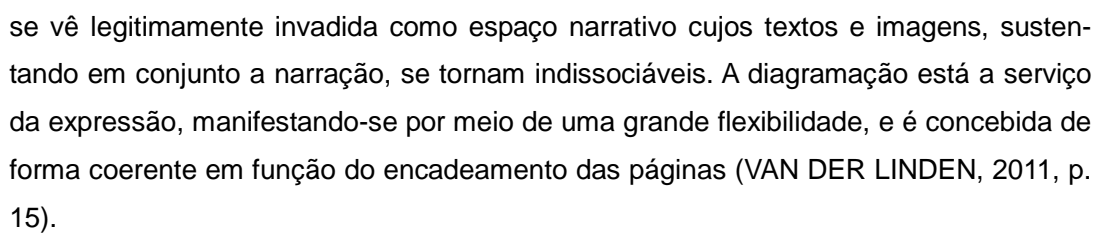

Um exemplo disso pode ser visto na imagem do livro infantil $O$ dia em que troquei meu pai por dois peixes dourados (Figura 1), ilustrado por Dave McKean. No quadro, o texto interage com a imagem e não obedece a uma diagramação rígida, de forma que se dispõe em blocos de texto que ocupam a totalidade da tela. A página dupla é tratada, então, como uma só imagem.

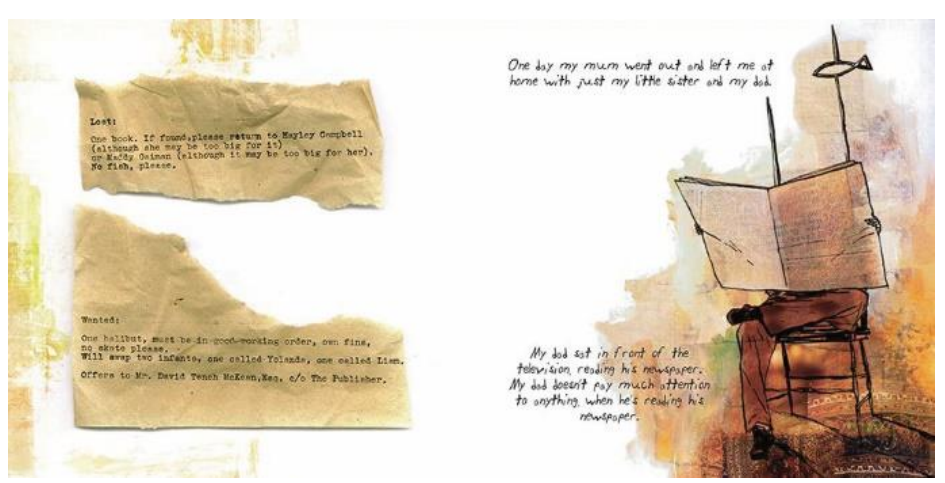

Figura 1 - O dia em que troquei meu pai por dois peixinhos dourados - Dave McKean - 2004

Segundo Van der Linden, na categoria Conjunção, "a própria noção de narrativa passa a ser questionada", e "[...] os livros ilustrados que atendem a esse tipo de organização não raro desenvolvem um discurso mais poético do que narrativo [...]" (2011, p. 70), uma vez que há grande liberdade na composição dos elementos na página, e a linearidade da história não é necessariamente prioritária. O livro Ma Maison (Figuras 2 e 3) é composto por um emaranhado de vinhetas e quadros onde são contados fragmentos da história agregados às imagens, conforme Van der Linden (2011). 


\title{
SULDESIGN CIENTÍFICO 2017
}

VIII Suldesign - encontro sul-americano

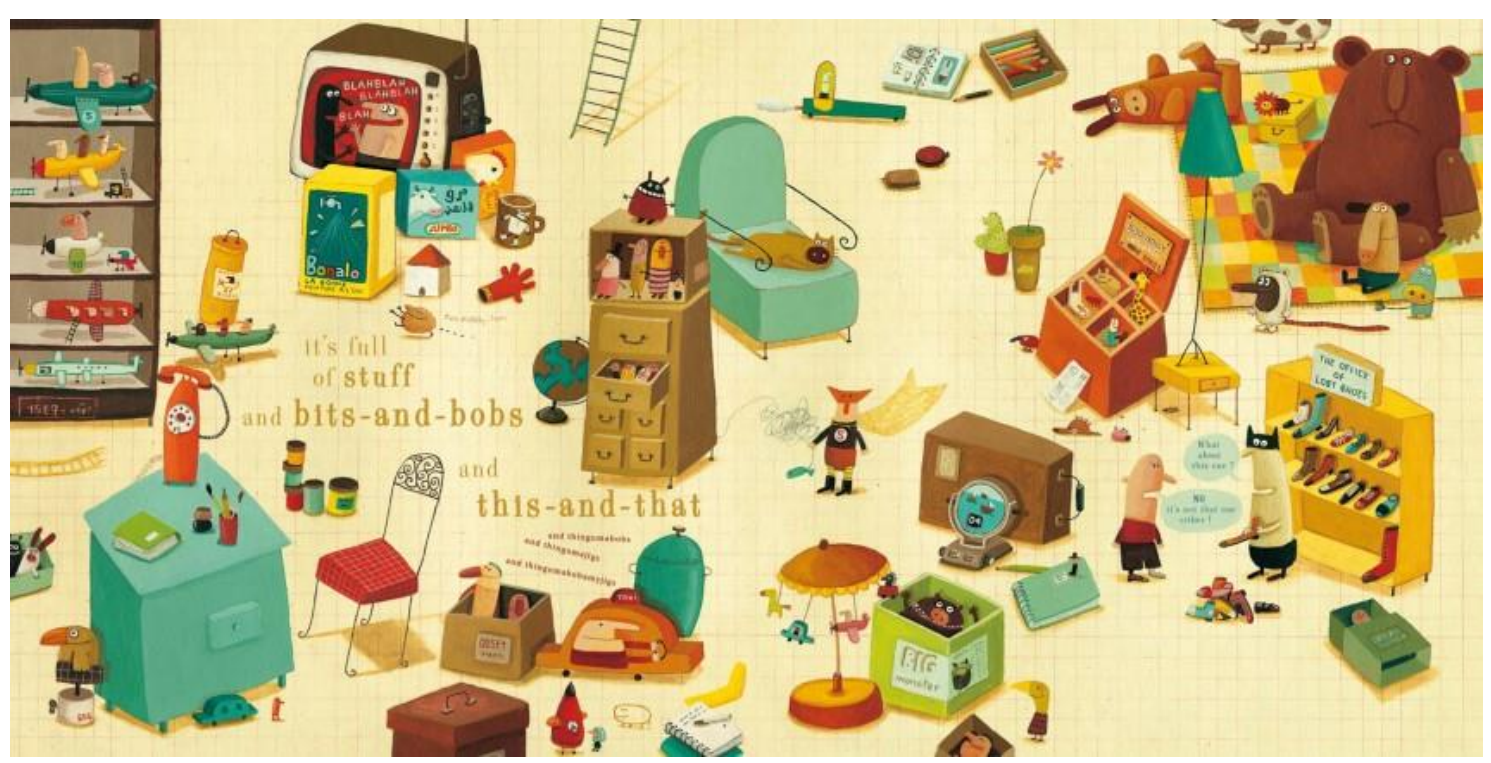

Figura 2 - Ma Maison - Delphine Durand - 2000

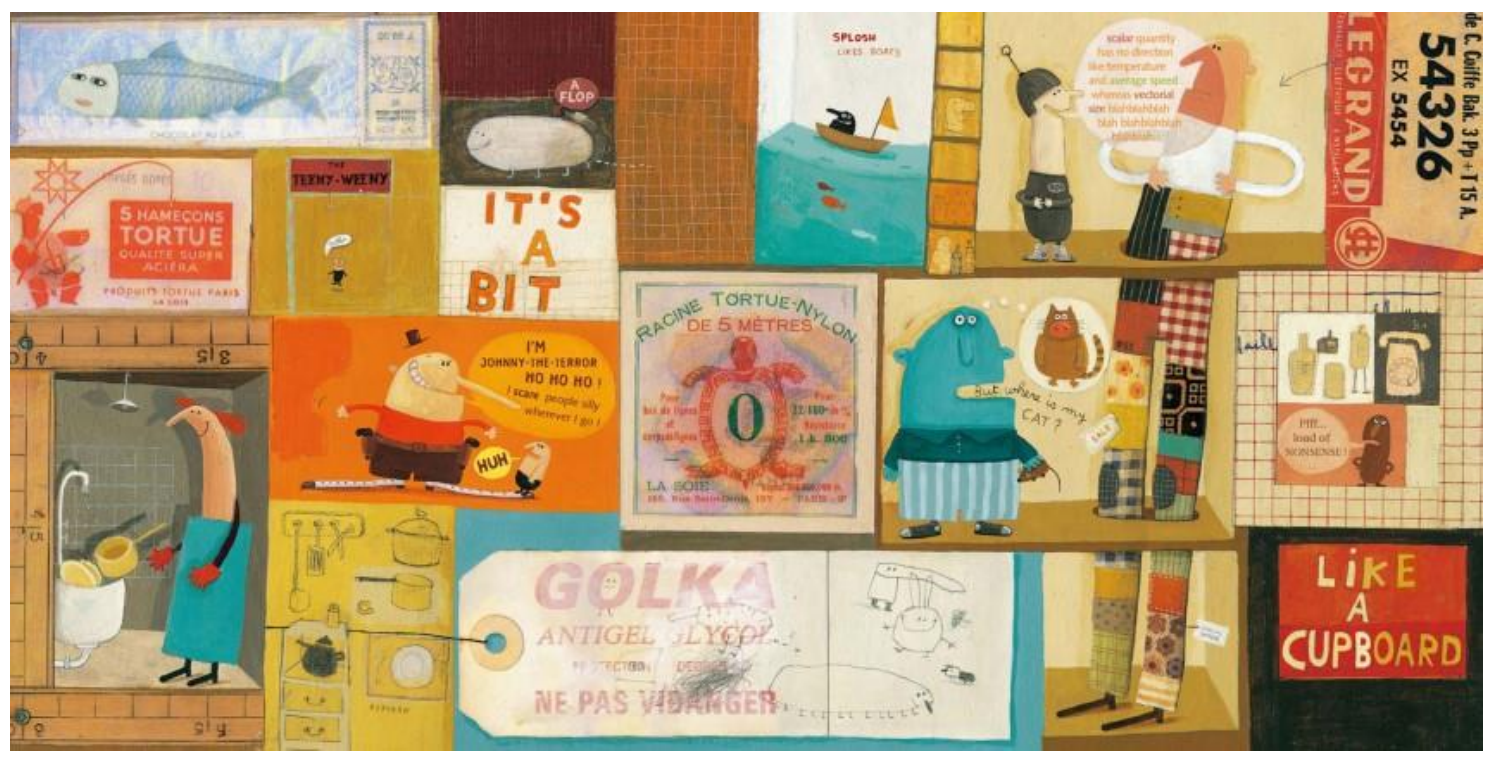

Figura 3 - Ma Maison - Delphine Durand - 2000

Embora o livro ilustrado possa ser uma categoria que engloba, também, a das novelas gráficas, algumas diferenças entre elas são visíveis. Com relação à categoria que Van der Linden denomina Compartimentação, a autora expressa que

\begin{abstract}
embora, em alguns casos, os criadores possam produzir páginas que se assemelhem a pranchas de história em quadrinhos, a diagramação do livro ilustrado contém algumas especificidades. Maiores em tamanho e em quantidade, as imagens são mais subordinadas ao movimento de continuidade entre as páginas. A compartimentação do espaço é menos importante, e as imagens se organizam principalmente em um nível ou dois [...] (VAN DER LINDEN, 2011, p. 69).
\end{abstract}

Já a novela gráfica - também conhecida como romance gráfico ou graphic novel - consiste em uma espécie de livro cuja história é contada através da arte sequencial. Essa arte sequencial, conforme Eisner (1989), lida com palavras, imagens e suas relações. 


\section{SULDESIGN CIENTÍFICO 2017}

VIII Suldesign - encontro sul-americano

Segundo Pépe Galvez, esse tipo de narrativa tem se consagrado como meio de expressão não só "[...] no campo da linguagem, mas também no da ambição expressiva, na vontade de abarcar objetivos mais profundos e mais complexos" (GALVEZ apud GARCíA, 2012, p. 35). Vejo essa complexidade de objetivos a que Galvez (apud GARCíA, 2012) se refere refletida em obras como Sandman (1988), Hackers (1989), Sinal e Ruído (1992), e mesmo em leituras voltadas para um público infanto-juvenil, como Mr. Punch (2010).

Ao contrário do que ocorre na maior parte dos livros ilustrados, nas novelas gráficas é comum a liberdade da diagramação dos textos e organização em pequenos blocos. Tem-se como exemplo a obra Hackers (Figura 4), onde McKean dispõe o texto da narrativa em pedaços assimétricos e divididos.

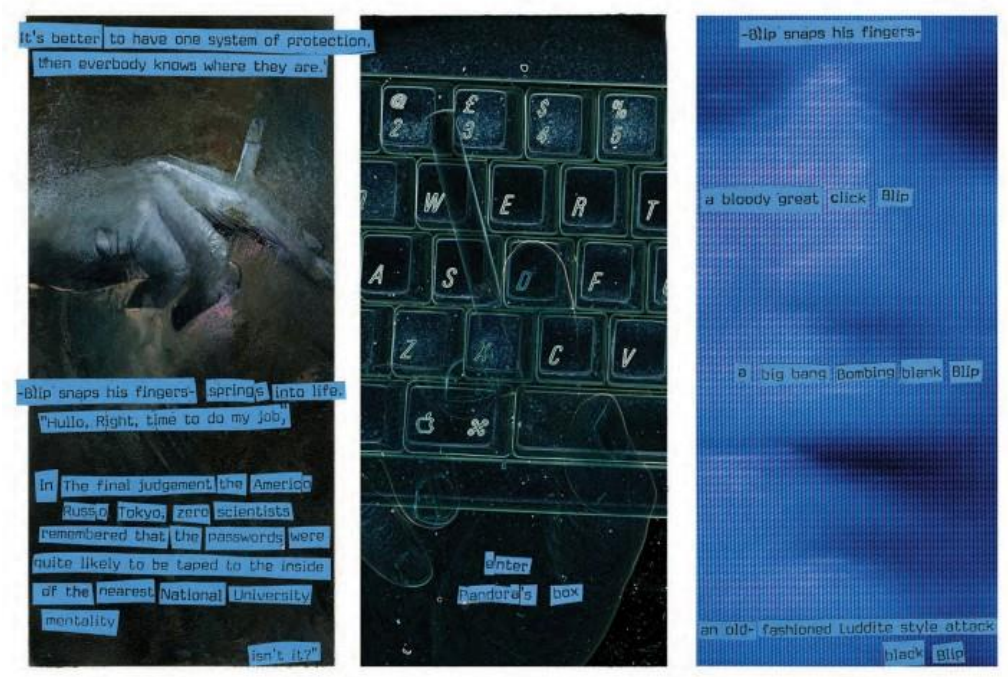

Figura 4 - Hackers - Dave Mckean - 1989

Em Mr. Punch (Figura 5), ilustrado por Dave McKean, as falas do personagem não mais se encontram nos balões convencionais das histórias em quadrinhos e atravessam quadros, interagindo com os blocos de texto e outros elementos da história em uma diagramação livre.

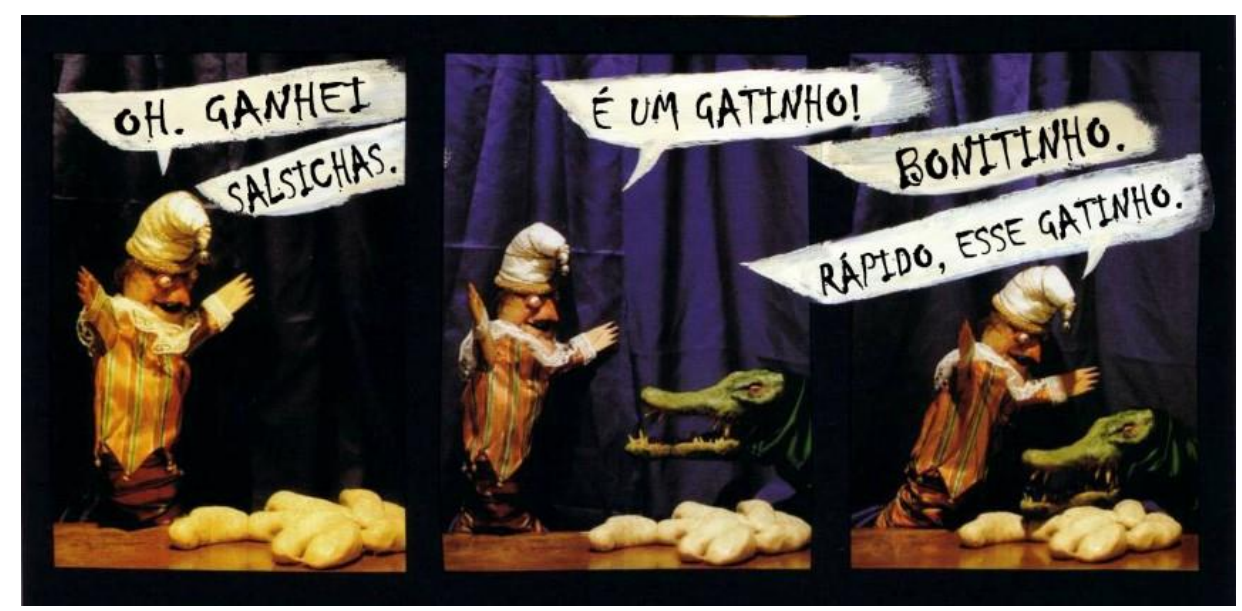

Figura 5 - Mr. Punch - Dave McKean - 2010

\section{UFPEL}




\section{SULDESIGN CIENTÍFICO 2017}

VIII Suldesign - encontro sul-americano

Posto isso, creio que é possível começar a perceber a proximidade entre ambas as áreas e a ambiguidade que as definições dessas categorias geram. Uma vez que seja possível relativizar os conceitos das categorias, podendo essas sofrerem variações em suas definições de acordo com a interpretação de cada autor, compreendo que esse lugar entre o livro ilustrado e a novela gráfica pode, igualmente, ser circunstancial e passível de modificações no decorrer do processo, em lugar de ser categorizado de maneira definitiva.

\section{O design autoral}

A partir das considerações de Rock (1996) e Weymar (2010) sobre o design autoral, encontrei o meu trabalho situado entre principalmente duas das categorias estipuladas: o livro ilustrado e o livro de artista. Percebo, inclusive, que essas categorias podem se mesclar, pois, de acordo com Van der Linden (2011), em muitos países, não há sequer um termo fixo para definir o livro ilustrado: em alguns lugares, ele é considerado um "caderno ou arquivo pessoal destinado a acolher desenhos, fotos, autógrafos, coleções diversas" (VAN DER LINDEN, 2011, p. 23), assim como pode ocorrer com o livro de artista.

Esse processo de registro imagético e textual citado por Van der Linden (2011) tornou-se importante no trabalho, pois, conforme Zeegen, "gerar ideias faz parte do papel do ilustrador, e a maioria das pessoas começa o processo no caderno de esboços", sendo esse caderno "[...] um lugar em que a comunicação é mais pessoal, onde o único público é o próprio artista, e em que a pura experimentação com conceitos e ideias pode começar" (ZEEGEN, 2009, p. 19).

Tendo esse processo experimental em vista, é possível fazer certa relação com a categoria do livro de artista, que, conforme Rock, "[...] é concreto, autorreferente e permite um leque de experimentos visuais sem o peso de cumprir papéis comerciais profanos", onde a função não mais existe (ROCK, 1996); ou seja, uma vez que não haja a obrigatoriedade de enquadrar o trabalho em um padrão passível de reprodução e comercialização, é possível mostrar, além dos resultados finalizados, todo o progresso da produção como uma forma de enriquecer o projeto e tornar seu processo transparente ao leitor.

Conforme Rock, os "livros de artista - usando palavras, imagens, estrutura e material para contar uma história ou invocar uma emoção - podem ser a forma mais pura de autoria gráfica" (ROCK, 1996). Weymar ratifica essas considerações expostas, dizendo que o livro de artista diz respeito a "[...] um design autorreferencial que trabalha com experimentos visuais e não precisa preencher tarefas comerciais" (2010, p. 122), colocando-o como possivelmente "[...] o modelo mais puro de design autoral [...]" (2010, p. 122).

\section{Sobre o conto}

O conto no qual esse trabalho foi inspirado trata da dicotomia entre a vida e a morte. Nele, são relatadas experiências de uma figura feminina, nunca definida, e sim apenas sugerida como uma entidade similar à morte, um ser responsável por fazer o trânsito das almas entre

\section{UFPEL}




\section{SULDESIGN CIENTÍFICO 2017}

VIII Suldesign - encontro sul-americano

os mundos. O nome, O campo de estrelas, faz referência aos opostos do céu estrelado e do campo: é a figura da morte, cujo lugar de origem é o céu estrelado (o plano espiritual), que vem ao mundo real (o plano material), representado pelos cenários, onde ambos os universos se encontram.

Para a produção do trabalho, foram desenvolvidas quatro duplas de páginas representando as capas de pontos nodais do enredo, os quais chamei de arcos de história. Vale salientar que essas capas que escolhi ilustrar estão ordenadas de acordo com a sequência da história, e não necessariamente obedecem a uma linearidade imediata: são pontos importantes resumidos que apresentam o teor da narrativa, e entre esses pontos há acontecimentos que foram suprimidos.

Além de expor a narrativa, penso ser relevante mostrar o processo no decorrer do trabalho, incluindo o storyboard (Figura 6), pois é nele que "[...] as ações estão definidas claramente e as intenções de composição são estabelecidas em uma direção específica, com um ponto de vista artístico particular" (WELLS, 2012, p. 114), tornando-o um ponto de partida relevante para inserir o leitor na ambientação da obra, visto que é nessa fase inicial que defino aspectos fundamentais para transmitir a atmosfera da história. Block complementa esse pensamento, afirmando que "o ponto de vista criado pelo roteirista é um elemento fundamental da narrativa, porque é a principal indicação para a escolha dos componentes visuais" (BLOCK, 2010, p. 267).
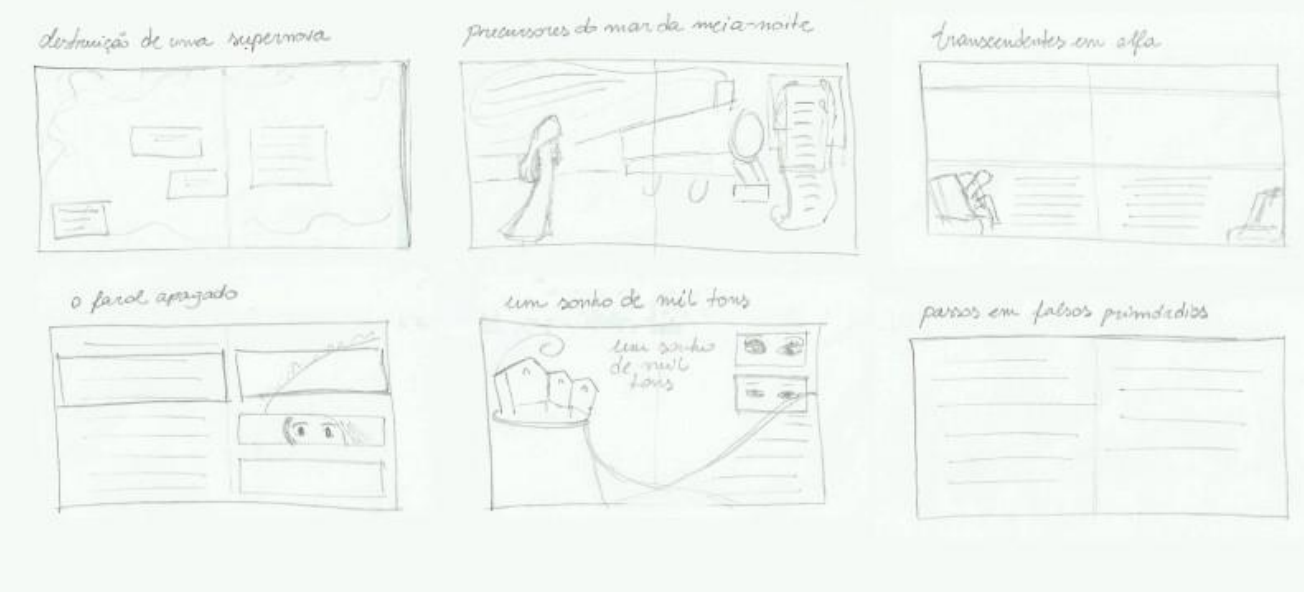

Figura 6 - Storyboard de O Campo de Estrelas - Karen Radünz - 2014

A ideia de ponto de vista trazida por Block (2010) se refere a uma apreensão geral sobre a história que se reflete na síntese das sensações que se deseja passar ao espectador. Dessa forma, segundo o mesmo autor, toda a narrativa é formada por uma parte de enredo somada aos componentes visuais, e é a junção desses elementos que compõe o todo e determina a significação e o sentido da narrativa. Os componentes visuais abarcam diferentes espaços - planos ou profundos -, ritmo, cor e movimento, e cada um destes componentes possui uma especificidade e propõe sensações diversas.

\section{UFPEL}




\section{SULDESIGN CIENTÍFICO 2017}

VIII Suldesign - encontro sul-americano

Assim, a paleta do projeto (Figura 7) mantém uma certa dose de contrastes, mas ao mesmo tempo engloba algo de silencioso e denso com o predomínio de variações de ocres e azuis. Conforme Lupton (2008), o significado das cores pode ser subjetivo, variando de acordo com a cultura e atribuindo a elas conotações diferentes. Salvo relativizações (conforme Israel Pedrosa (2009), cores quentes e frias podem apresentar variações de acordo com a localização e intensidade de outras dentro da composição), os amarelos estão presentes no grupo de cores quentes, enquanto os azuis fazem parte das cores frias.

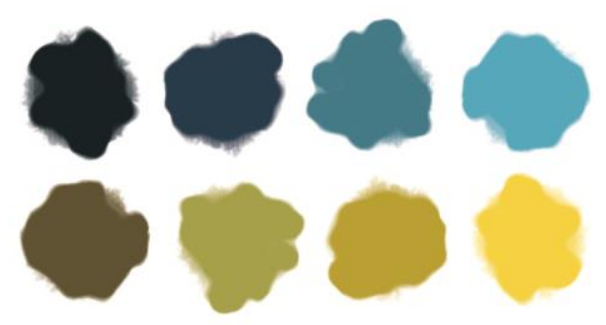

Figura 7 - Paleta de cores para O Campo de Estrelas - Karen Radünz - 2014

$\mathrm{Na}$ história, os azuis, visíveis em grande parte dos elementos, simbolizam o presente, frio e solitário, onde a personagem transita, além de fazerem menção à transição entre um mundo e outro. Já o amarelo e o ocre fazem referência tanto ao passado, um tempo de lugares mais tranquilos na história, quanto aos sonhos e flashbacks, onde os personagens se encontram a salvo em um mundo paralelo onírico.

As imagens não tocam o chão, desfazendo-se nas extremidades ou sendo cortadas pelos limites do suporte com seu formato específico, inserindo-se e reforçando a ideia da ambientação fantástica e onírica. A concepção dos personagens passou por estudos (Figuras $8 \mathrm{e}$ 9) até, por fim, devido à atmosfera misteriosa que a trama contém, optar-se por suprimir sua presença, dando ênfase aos cenários como os focos principais.

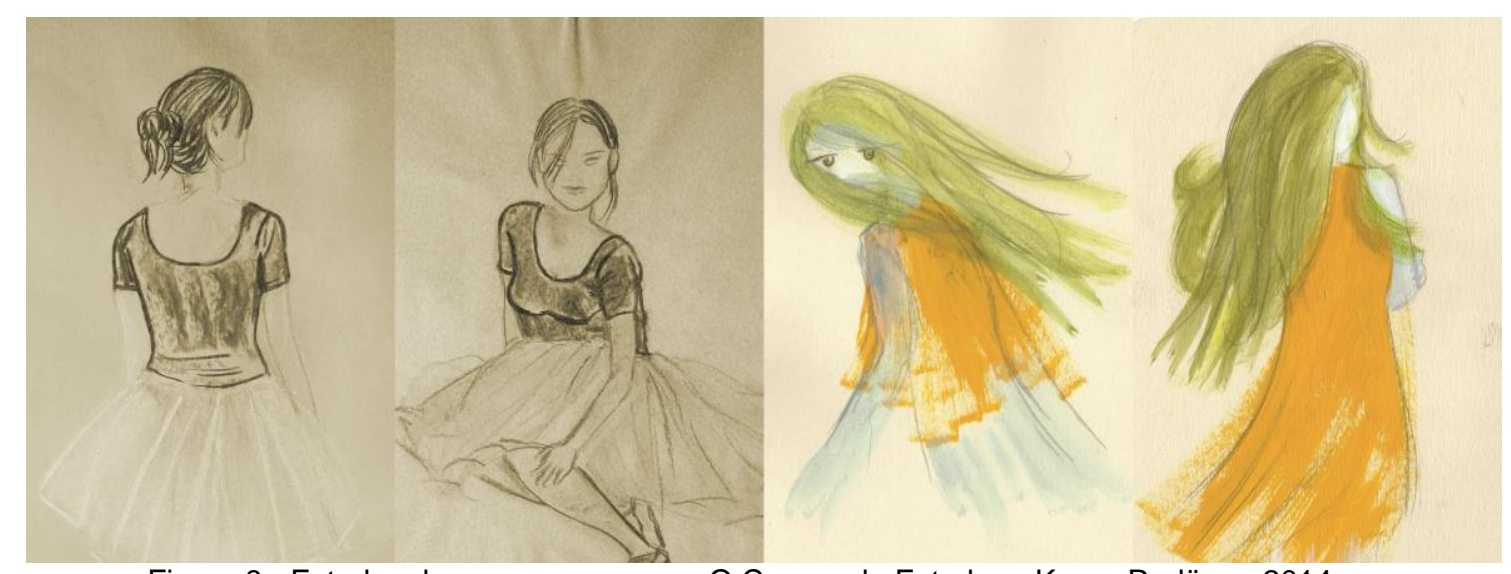

Figura 8 - Estudos de personagem para O Campo de Estrelas - Karen Radünz - 2014 


\section{SULDESIGN CIENTÍFICO 2017}

VIII Suldesign - encontro sul-americano

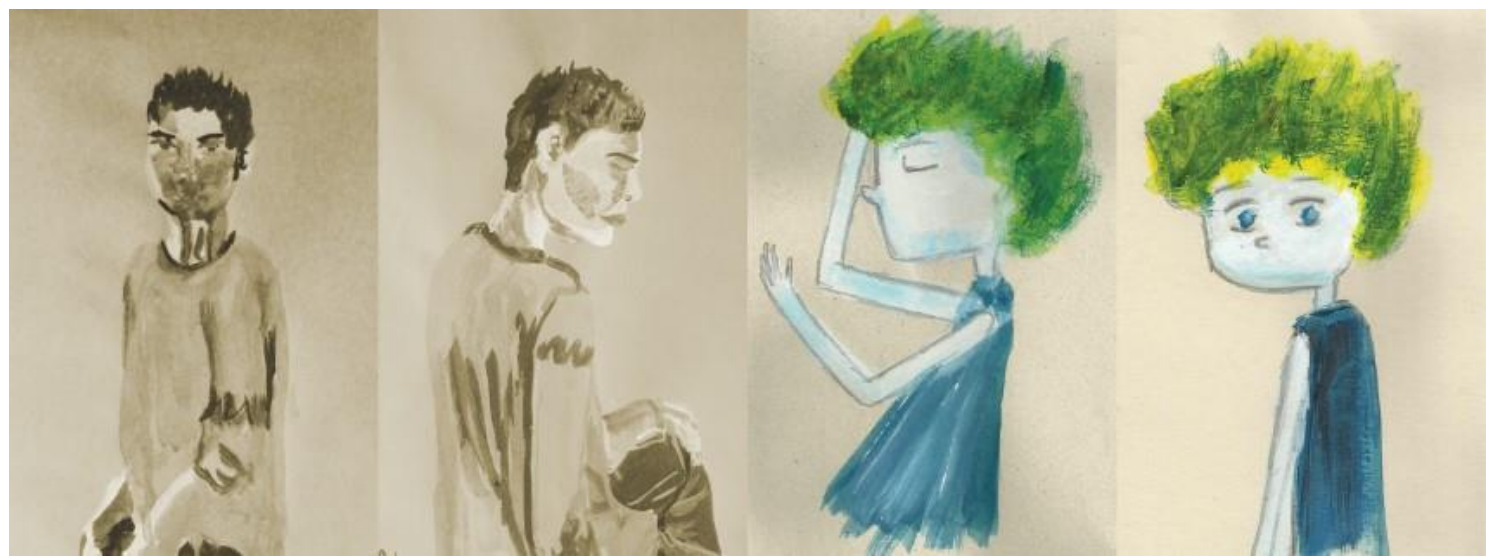

Figura 9 - Estudos de personagem para O Campo de Estrelas - Karen Radünz - 2014

Os cenários são desenvolvidos a partir de montagens com ilustrações e fotografias. Acima das imagens, pinceladas digitais sugerem a fluidez da história e diluem o tom de realismo presentes nelas. Uma série de estudos utilizando a fotografia foi feita antes de, por fim, decidir usá-la como um elemento de apoio, tornando a sua imagem original, a partir de tratamento, sobreposição de texturas e desenhos, praticamente irreconhecível nos cenários, servindo de complemento aos desenhos sobrepostos (Figura 10).

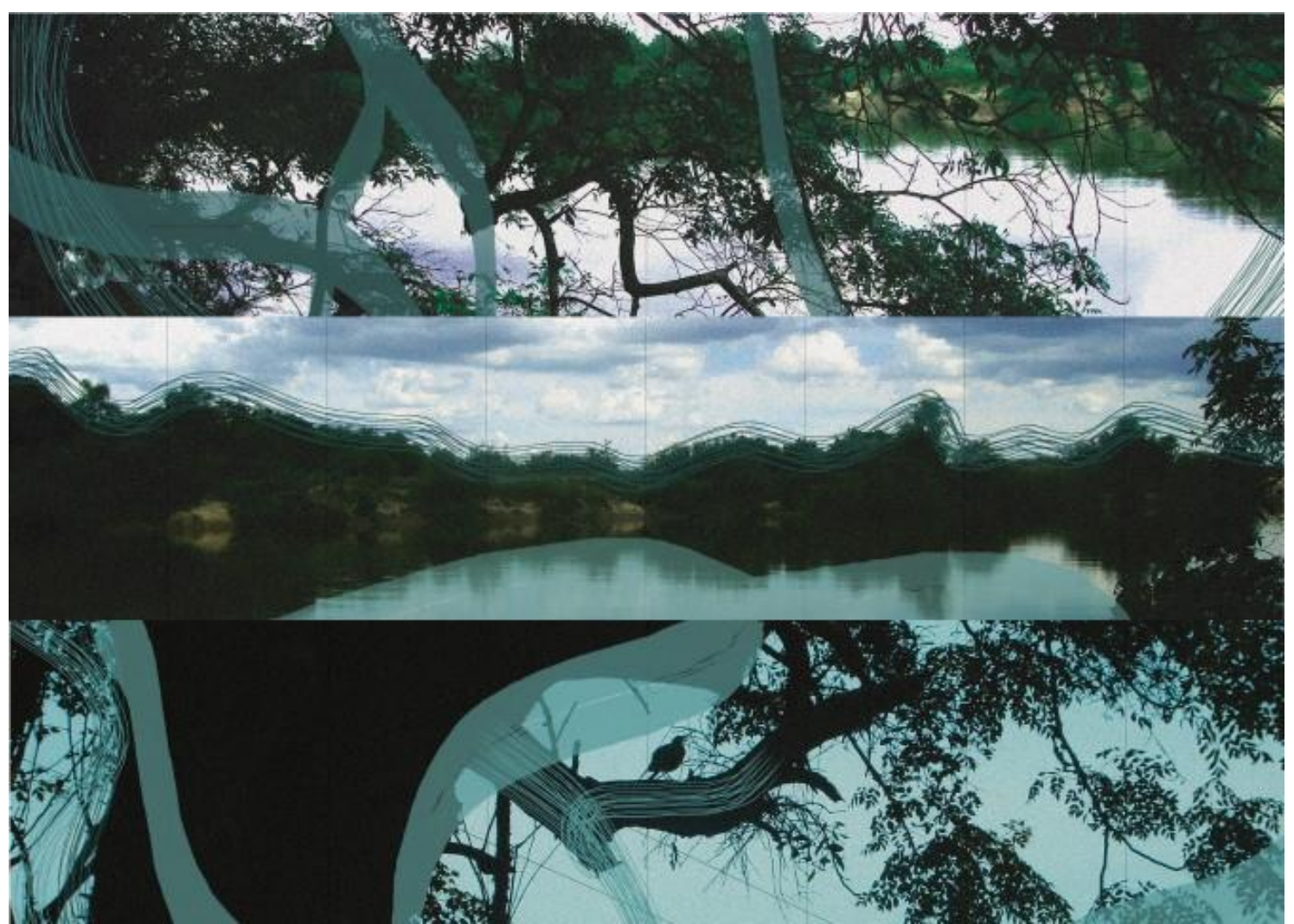

Figura 10 - Estudos de cenários para O Campo de Estrelas - Karen Radünz - 2014

Com o intuito de reforçar a ideia de lugares indefinidos, os cenários do conto-ilustrado são compostos de texturas, camadas e transparências sobrepostas (Figura 11), sendo esses dois últimos elementos correlatos, conforme Lupton (2008). Um pensamento de Pablo Picasso exposto pela autora complementa essa abordagem, dizendo que "sob as cidades, você sempre encontra outras cidades" (apud LUPTON, 2008, p. 127), o que pode ser rela-

\section{UFPEL}




\section{SULDESIGN CIENTÍFICO 2017}

VIII Suldesign - encontro sul-americano

cionado com um lugar que esconde outro lugar, ou algo que não se define totalmente: a "transparência significa uma percepção simultânea de diferentes localizações espaciais", segundo Gyorgy Kepes (apud LUPTON, 2008, p. 147).

Referindo-se à textura concreta, Lupton ainda diz que "a qualidade física que resulta dos atos de recortar, queimar, marcar e extrair, repetidamente, cria superfícies de texturas concretas com forte apelo" (LUPTON, 2008, p. 54), que, creio, aliadas à manipulação virtual, resulte em uma gama variada de possibilidades de composições.

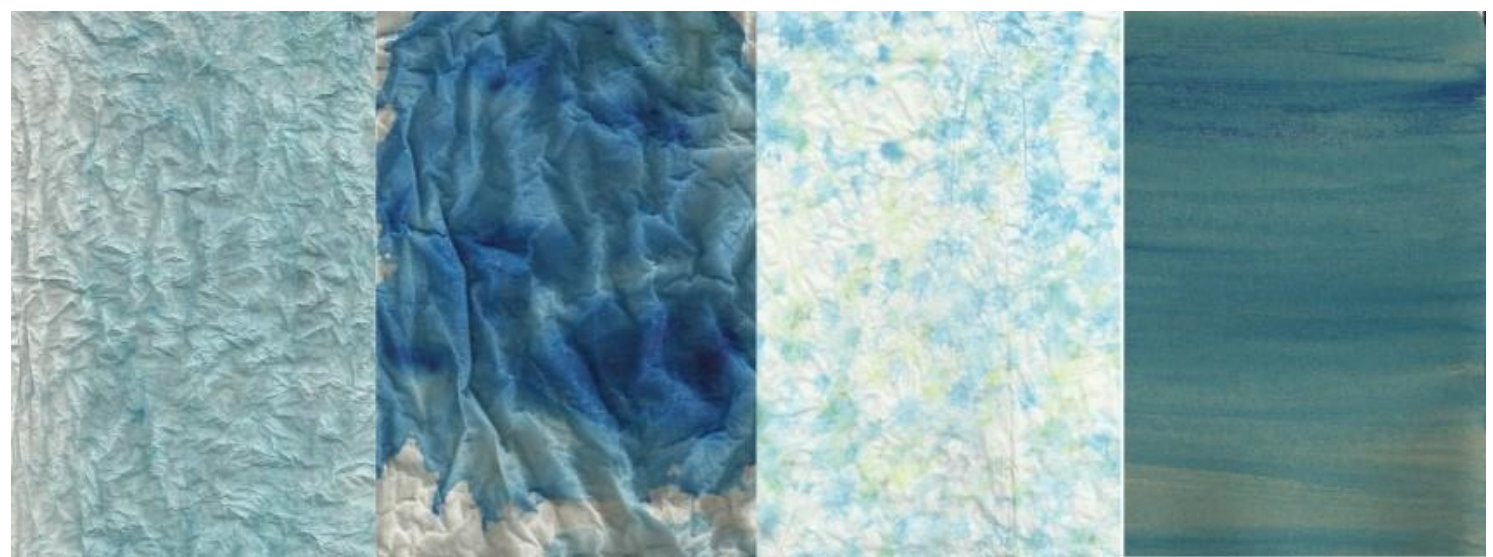

Figura 11 - Estudos de texturas para O Campo de Estrelas - Karen Radünz - 2014

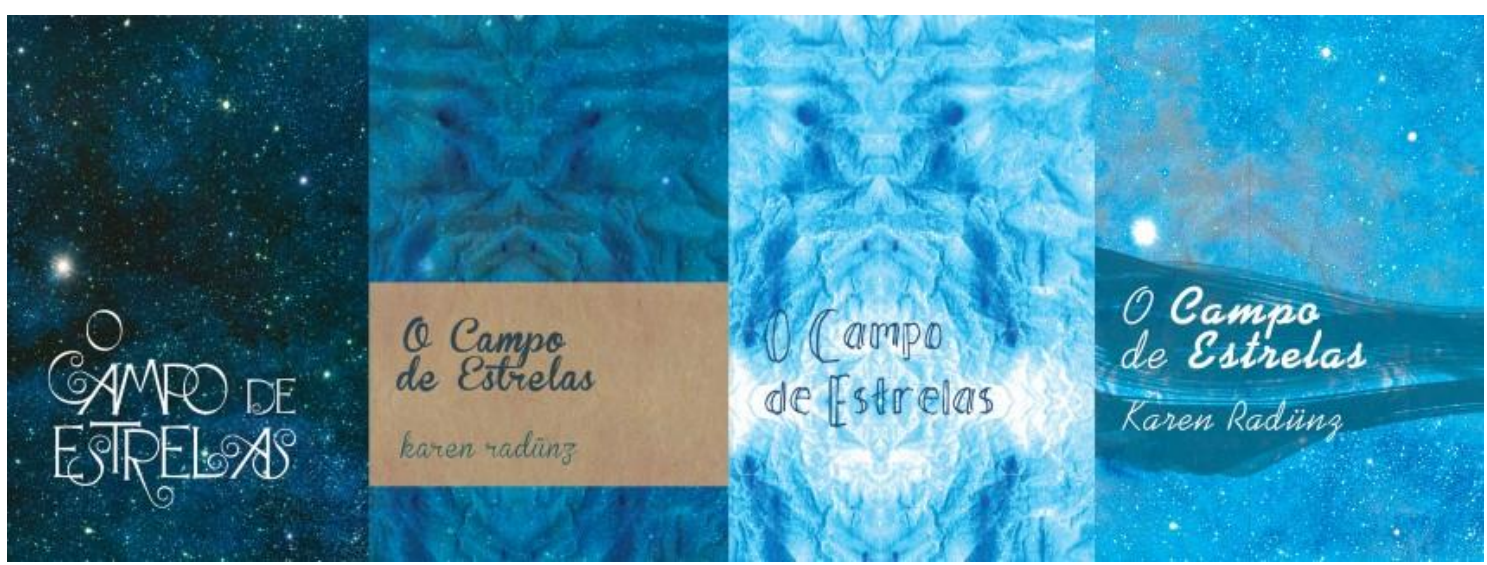

Figura 12 - Estudos de capas para O Campo de Estrelas - Karen Radünz - 2014

Assim como acontece em Sandman, de acordo com os relatos de McKean, "o conceito de que o protagonista [...] deveria estar constantemente presente nas capas foi o primeiro a cair" (RADÜNZ, 2012, p. 3). Com o intuito de sugerir uma sensação do que seja o conto, sem, contanto, usar uma figuração ou representação de algo, optei por utilizar a ideia do céu e estrelas com as sobreposições de texturas em lugar de apresentar uma ilustração que mostrasse os personagens em si (Figuras 12 e 13), também pelo fato dos cenários terem se tornado os protagonistas da narrativa. 


\section{SULDESIGN CIENTÍFICO 2017}

VIII Suldesign - encontro sul-americano

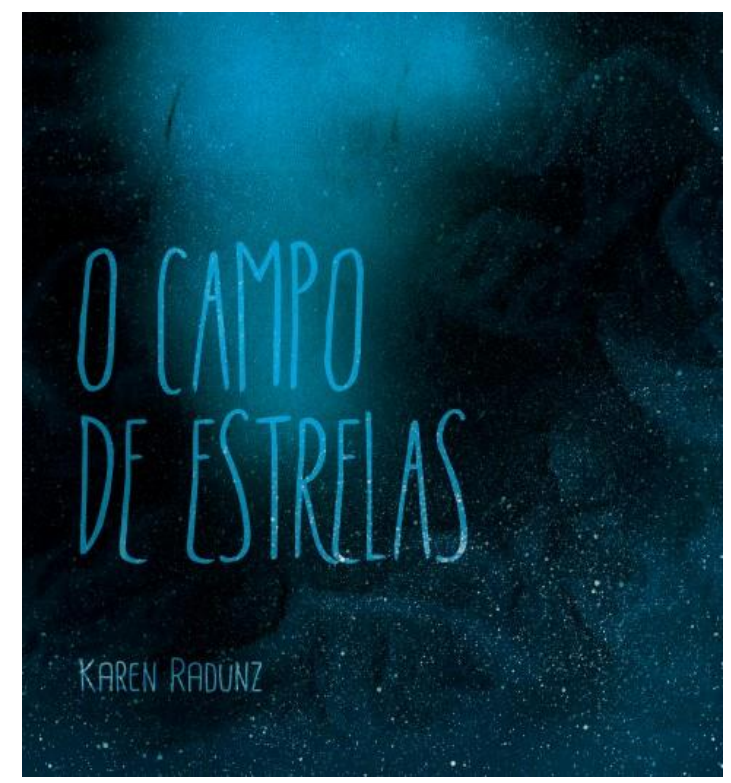

Figura 13 - Capa final de O Campo de Estrelas - Karen Radünz - 2014

A tipografia escolhida para o título do conto-ilustrado, de aparência alongada, contrasta com o formato escolhido para o livro, próximo ao quadrangular. Nos capítulos do conto-ilustrado, os títulos parecem ser absorvidos pelo fundo de estrelas, mesclando-se a eles, conservando certa transparência e tornando-se parte da imagem. Embora a irregularidade presente nos caracteres confira um aspecto manual ao título, simulando uma escrita à mão, a legibilidade necessária para a compreensão se mantém, em parte pelo contraste entre o claro e o escuro - esse último presente no fundo -, como também pelo seu amplo tamanho.

Essa mistura de elementos diversificados incluindo camadas, transparências, sobreposições e o trabalho com técnicas diferentes conferem à produção os aspectos necessários para transmitir a atmosfera da trama, sendo essa aura incomum, fantástica e onírica um elemento essencial da história, como é possível ver nas páginas ilustradas, na Figura 14. 


\section{SULDESIGN CIENTÍFICO 2017}

VIII Suldesign - encontro sul-americano

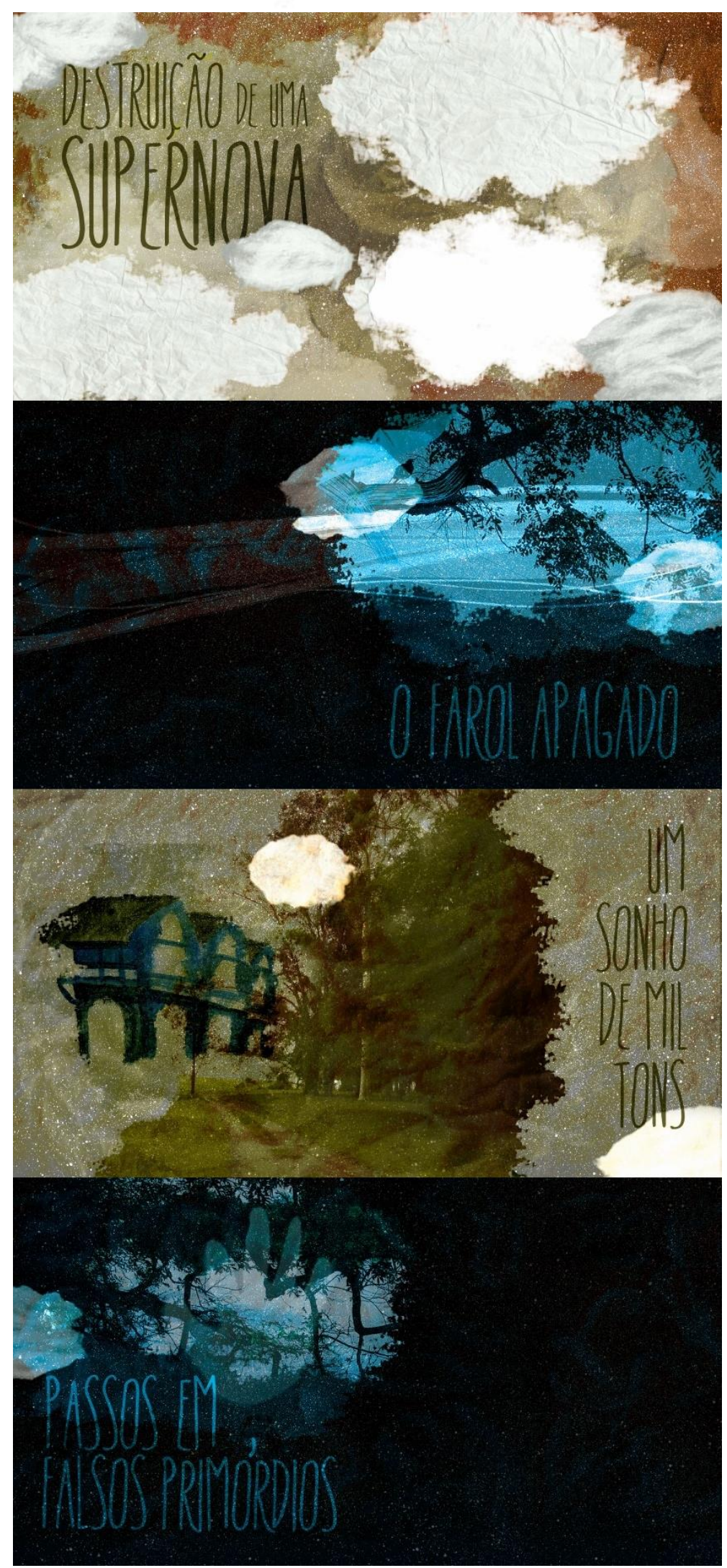

Figura 14 - Páginas ilustradas de O Campo de Estrelas - Karen Radünz - 2014

\section{Finalizando o interminado}

Sintetizando o que percebo de mais importante no processo de construção desse trabalho, que se deu como uma construção constante, parece relevante salientar alguns pontos. Com relação à metodologia adotada no desdobramento desse percurso, constatei que o não-

\section{UFPEL}




\section{SULDESIGN CIENTÍFICO 2017}

VIII Suldesign - encontro sul-americano

método colocado por Feyerabend tornou possível que a prática auxiliasse na teoria e que 0 oposto também acontecesse, contribuindo para que ambas as fases se tornassem coesas e se desenvolvessem concomitantemente.

O já citado lugar híbrido que busquei entre o livro ilustrado e a novela gráfica mostrou-se possível de ser encontrado, embora a categorização não tenha se mostrado o ponto fundamental para o desenvolvimento do trabalho. Isso ocorreu tanto na prática do conto-ilustrado, onde características de ambas as categorias se mesclaram, como na fase teórica, a partir, principalmente, das constatações de Van der Linden (2011) aliadas aos exemplos de trabaIhos de ilustração de Dave McKean, onde foi possível perceber as similaridades entre o livro ilustrado e a novela gráfica e onde essas semelhanças se encontram.

Creio, também, que esse trabalho tenha aberto precedentes para reflexões acerca de produções inseridas no campo do design autoral, principalmente no que tange às áreas dos livros ilustrados e novelas gráficas. Como Lupton (2011) coloca, o designer possui os artifícios necessários para se tornar o pensador e produtor do seu próprio trabalho.

Além dessas questões apresentadas, o trabalho todo foi um processo de conhecimento, reconhecimento e síntese, que abarca parte do que aprendi durante a trajetória acadêmica, desde as questões mais pontuais, como a pesquisa, a reflexão e a técnica, até, principalmente, no que tange à relação com o design e em como aprimorar o que foi aprendido a partir desse todo.

\section{Referências}

BECCARI, Marcos. Contra o método: o anarquismo epistemológico de Paul Feyerabend. In: Filosofia do Design. 2010. Disponível em: <http://filosofiadodesign.com/contra-ometodo >. Acesso em: 19 de abril de 2017.

BLOCK, Bruce. A narrativa visual: criando a estrutura visual para cinema, TV e mídias digitais. São Paulo: Elsevier, 2010.

EISNER, Will. Quadrinhos e arte sequencial. São Paulo: Martins Fontes, 1989.

FEYERABEND, Paul. Contra o método. Rio de Janeiro: Francisco Alves, 1977.

GAIMAN, Neil. Sandman: Prelúdios e Noturnos (Volume I). Rio de Janeiro: Pixel Media, 2008.

GARCÍA, Santiago. A Novela Gráfica. São Paulo: Martins Fontes, 2012.

LUPTON, Ellen. Livro Independente: um guia para autores, artistas e designers. São Paulo: Rosari, 2011.

LUPTON, Ellen. Novos Fundamentos do Design. São Paulo: Cosac Naify, 2008.

PEDROSA, Israel. Da cor à cor inexistente. São Paulo: Senac, 2009.

\section{UFPEL}




\section{SULDESIGN CIENTÍFICO 2017}

VIII Suldesign - encontro sul-americano

RADÜNZ, Karen. Elementos de Design nas capas da série de quadrinhos Sandman. 2012. 11

f.

Disponível

em:

<http://cearte.ufpel.edu.br/integradesign/arquivos/artigos/grafico/karenradunz_designgrafico _elementosdedesignFINAL.pdf>. Acesso em: 19 de abril de 2017.

ROCK, Michael. O Designer enquanto autor. Tradução de Eduardo Souza. In: Filosofia do Design. 2013. Disponível em: <http:/filosofiadodesign.com/o-designer-enquanto-autor>. Acesso em: Acesso em: 19 de abril de 2017.

ROCK, Michael. The designer as author. In: Eye Magazine. 1996. Disponível em: <http://www.eyemagazine.com/feature/article/the-designer-as-author>. Acesso em: 19 de abril de 2017.

VAN DER LINDEN, Sophie. Para ler o livro ilustrado. São Paulo: Cosac Naify, 2011.

WELLS, Paul. Desenho para animação. Porto Alegre: Bookman, 2012.

WEYMAR, Lúcia Bergamaschi Costa. Design entre aspas: indícios de autoria nas marcas da comunicação gráfica. 2010. 332 f. Tese (Doutorado), Faculdade de Comunicação Social, PUCRS. Porto Alegre: PUCRS, 2010.

ZEEGEN, Lawrence; CRUSH. Fundamentos da llustração. Porto Alegre: Bookman, 2009. 